\title{
LMIIE EDIION
}

Prints from the Original Oils of Award Winning Artist H.T. BECKFR

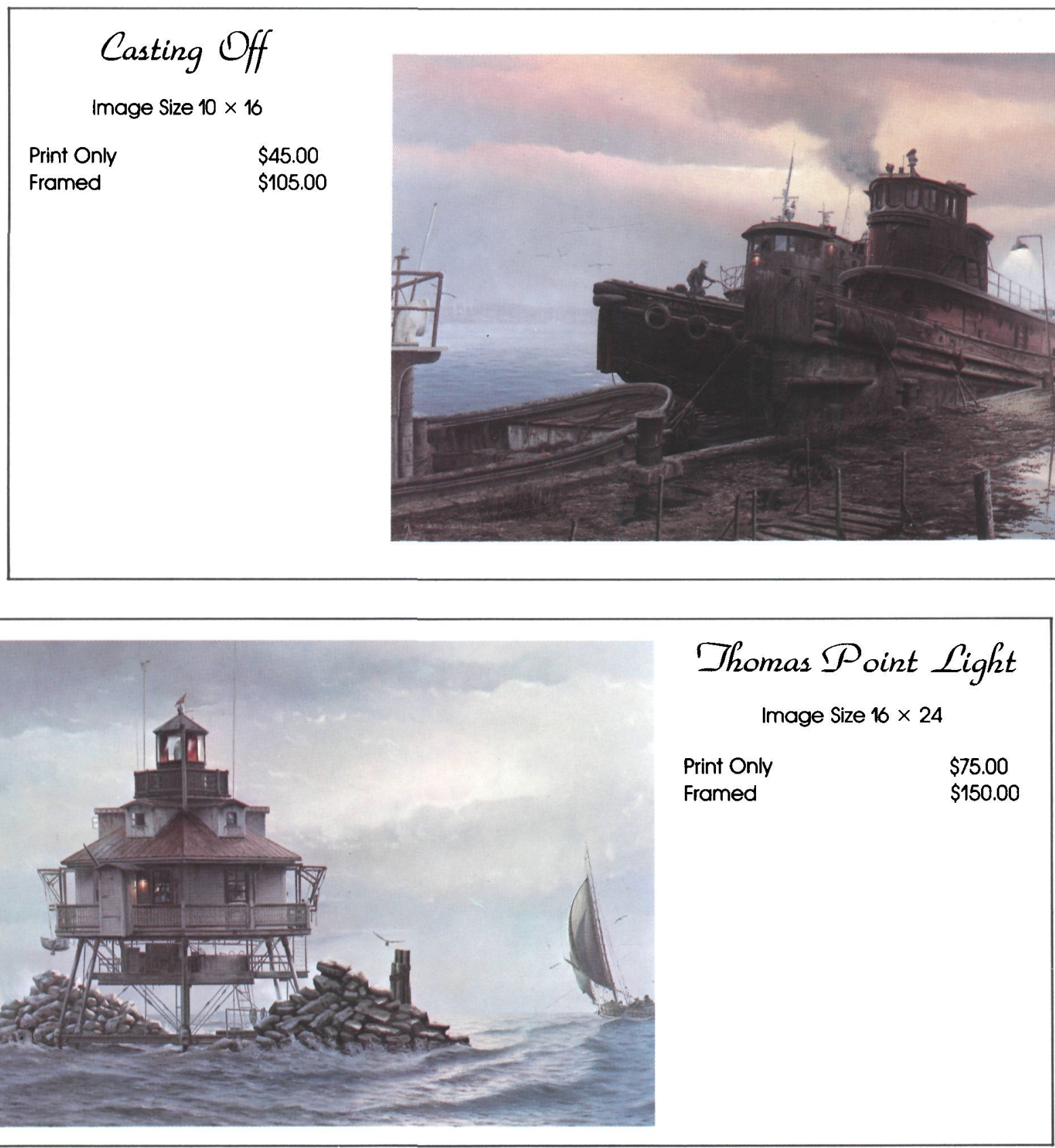

H.T. Becker's work is perceptive and clear. He uses luminescent techniques that seem to spread a diffused light over the surface of the painting. This combined with the realism in which

his work is created evokes a haunting quality. Mr. Becker has won numerous awards and his works are in public and private collections nationally and abroad. Editions limited to 950 signed and numbered by the artist. Printed in full color.

To order, please send your check or money order to:

First Impressions, 6900 Grove Road, Thorofare, New Jersey 08086

(N.J. residents add $6 \%$ sales tax.) 
